\title{
MEMBANGUN SISTEM INFORMASI PEMBAYARAN BIAYA KOMITE BERBASIS JARINGAN DENGAN METODE BERORIENTASI OBYEK : STUDI KASUS SMAN 2 PANGKALPINANG
}

\author{
Marini \\ Program Studi Komputerisasi Akuntansi, STMIK Atma Luhur \\ Jln. Raya Sungailiat-Selindung Lama, Pangkalpinang-Bangka Belitung \\ Email: arinimarini44@yahoo.co.id
}

\begin{abstract}
Abstrak
Penelitian yang dilakukan bertujuan untuk dapat membuat sistem informasi pembayaran biaya komite berbasis jaringan pada SMU Negeri 2 pangkalpinang. Diharapkan memilki manfaat untuk memberikan informasi-informasi yang dibutuhkan oleh setiap elemen dalam sekolah dan juga wali murid. Untuk mencapai tujuan tersebut, alat bantu yang digunakan antara lain, Bahasa Pemprograman, alat bantu pengembangan sistem yakni FOD, SDLC, UML dan ERD dan Basis Data, metode pengujian menggunakan metode berorientasi obyek. Spesifikasi software menggunakan Visual Basic 6 sebagai bahasa pemrograman dan Access sebagai database. Dari hasil penelitian yang diperoleh, maka saransaran sangat dibutuhkan untuk dapat diberikan penulis yaitu system ini masih dapat dikembangkan agar menjadi sistem informasi pembayaran biaya komite berbasis jaringan yang lebih baik dan efisien sesuai dengan kebutuhan dan perkembangan teknologi dan juga diperlukan pelatihan dalam bidang teknologi informasi sehingga penerapannya dapat dilaksanakan dengan baik.
\end{abstract}

Kata Kunci : System, informasi, pembayaran, Uang komite, Jaringan.

\section{Pendahuluan}

\subsection{Latar Belakang}

Perkembangan teknologi informasi yang semakin pesat saat ini menunjukkan bahwa betapa pentingnya peranan informasi bagi suatu organisasi, maka dari itu diperlukan suatu alat yang dapat mengolah data dan informasi dalam skala besar secara cepat, tepat dan akurat sehingga informasi yang diterima tidak terlambat. Salah satu yang dapat diandalkan adalah komputer.

Dalam upaya peningkatan mutu sumber daya manusia dan proses kelancaran dari administrasi sekolah khususnya sistem pembayaran uang komite yang membutuhkan kecepatan dan ketepatan agar pelayanan terhadap masyarakat khususnya wali murid dan murid itu sendiri dapat dilayani dengan profesional.

SMU Negeri 2 merupakan salah satu elemen pendidikan yang memanfaatkan peralatan TIK (Teknologi Informasi Komunikasi) sebagai peralat yang dapat membantu permasalahan tidak hanya untuk kegiatan belajar mengajar saja atau dalam hal surat menyurat rutin akan tetapi mencoba membangun sebuah sistem administrasi pembayaran uang komite secara komputerisasi. Oleh karena itulah penulis mencoba mensolusikan permasalahan administrasi yang masih dilakukan secara manual pada sekolah dengan Standard Nasional ini. SMU Negeri 2 pangkalpinang sebagai suatu institusi pendidikan yang sedang berkembang dan selalu ingin mengikuti perkembangan teknologi informasi yang sedang berkembang. Bidang administrasi keuangan yang selama ini masih terasa sulit untuk dikerjakan karena menggunakan format manual menarik penulis untuk meneliti dan mengembangkan sistem informasi administrasi keuangan berbasis komputer.

\subsection{Permasalahan}

Permasalahan yang sering muncul adalah pelayanan pembayaran biaya komite dan pencatatan yang masih manual menyebabkan terkadang terjadi human error, kurang tersusun rapi dalam pengarsipan dokumen, penyusunan laporan, baik laporan bulanan, per semester, maupun laporan tahunan adalah sulitnya mengumpulkan data pembayaran uang komite yang terpisah-pisah di beberapa buku keuangan, kurang lengkap dalam pencatatan sistem informasi administrasi pembayaran uang komite.

\subsection{Ruang Lingkup Penelitian}

Penelitian ini mempunyai ruang lingkup yaitu suatu aplikasi yang terkomputerisasi dengan memanfaatkan Jaringan sebagai pintu masuk keluarnya informasi atau biasa disebut membangun sistem informasi untuk pelayanan pembayaran uang komite siswa yang terdaftar 
sebagai Murid SMU Negeri 2. Pembayaran uang komite merupakan kegiatan dimana seorang wali murid atau murid membayar kewajibannya demi kelancaran dari proses belajar mengajar kepada pihak sekolah.

\subsection{Tujuan dan Manfaat Penelitian}

Penelitian ini diharapkan dapat memperbaiki sistem yang ada dengan harapan agar pengolahan yang selama ini masih dilakukan secara manual, dapat dipermudah dan dipercepat kinerjanya dengan memberikan solusi berupa rancangan sistem yang terkomputerisasi. Sistem komputerisasi ini juga diharapkan dapat mendukung tercapainya tujuan sebagai berikut : Meningkatkan mutu pelayanan dibidang administrasi keuangan agar lebih baik lagi dan mudah mengidentifikasi penyimpanan data, Dapat menerima dan menyajikan informasi dengan mudah dan sesuai dengan yang dibutuhkan, Meningkatkan efektifitas dalam pengolahan agar dapat menghasilkan informasi yang dibutuhkan dengan lengkap serta dapat dihasilkan setiap saat jika diperlukan, untuk menekan seminimal mungkin terjadinya kesalahan-kesalahan dalam proses perncatatan maupun perhitung atas transaksi pembayaran, untuk mendukung transaksi pembayaran sehingga menghasilkan laporan yang cepat, tepat, dan akurat.

\section{TINJAUAN PUSTAKA}

\subsection{Siklus Hidup Pengembangan Sistem} (SDLC)

HM., Yogiyanto 1995. SDLC berfungsi untuk menggambarkan tahapan-tahapan utama dan langkah-langkah dari setiap tahapan ${ }^{[3]}$ Dalam perkembangannya SDLC dilengkapi oleh metode pengembangan sistem. Adapun salah satu model pengembangan sistem tersebut adalah sebagai berikut:

Waterfall. Model satu arah yang dimulai dari tahap persiapan sampai perawatan. Model ini sering dipergunakan oleh analais sistem pada umumnya.

Tahapan-tahapan dalam model Waterfall

\section{1) Analisis}

Seluruh kebutuhan software harus bisa didapatkan dalam fase ini, termasuk didalamnya kegunaan software yang diharapkan pengguna dan batasan software. Informasi ini biasanya dapat diperoleh melalui wawancara, survey atau diskusi. Informasi tersebut dianalisis untuk mendapatkan dokumentasi kebutuhan pengguna untuk digunakan pada tahap selanjutnya.

\section{2) Desain}

Tahap ini dilakukan sebelum melakukan coding. Tahap ini bertujuan untuk memberikan gambaran apa yang seharusnya dikerjakan dan bagaimana tampilannya. Tahap ini membantu dalam menspesifikasikan kebutuhan hardware dan sistem serta mendefinisikan arsitektur sistem secara keseluruhan.

3) Implementasi

Dalam tahap ini dilakukan pemrograman. Pembuatan software dipecah menjadi modulmodul kecil yang nantinya akan digabungkan dalam tahap berikutnya. Selain itu dalam tahap ini juga dilakukan pemeriksaaan terhadap modul yang dibuat, apakah sudah memenuhi fungsi yang diinginkan atau belum.

4) Pengujian.

Di tahap ini dilakukan penggabungan modul-modul yang sudah dibuat dan dilakukan pengujian ini dilakukan untuk mengetahui apakah software yang dibuat telah sesuai dengan desainnya dan masih terdapat kesalahan atau tidak.

5) Perawatan.

Ini merupakan tahap terakhir dalam model waterfall. Software yang sudah jadi dijalankan serta dilakukan pemeliharaan. Pemeliharaan termasuk dalam memperbaiki kesalahan yang tidak ditemukan pada langkah sebelumnya. Perbaikan implementasi unit sistem dan peningkatan jasa sistem sebagai kebutuhan baru.

\subsection{Jaringan Komputer.}

Menurut Yuhefizar (2003). Jaringan komputer adalah sebuah kumpulan komputer, printer dan peralatan lainnya yang terhubung dalam satu kesatuan ${ }^{[11]}$. Informasi dan data bergerak melalui kabel-kabel atau tanpa kabel sehingga memungkinkan pengguna jaringan komputer dapat saling bertukar dokumen dan data, mencetak pada printer yang sama dan bersama-sama menggunakan hardware/software yang terhubung dengan jaringan. Setiap komputer, printer atau periferal yang terhubung dengan jaringan disebut node. Sebuah jaringan komputer dapat memiliki dua, puluhan, ribuan atau bahkan jutaan node.

Jenis-Jenis Jaringan Komputer Secara umum jaringan komputer dibagi atas lima jenis, yaitu ;

(1) Local Area Network (LAN)

Merupakan jaringan milik pribadi di dalam sebuah gedung atau kampus yang berukuran sampai beberapa kilometer. LAN seringkali digunakan untuk menghubungkan komputerkomputer pribadi dan workstation dalam kantor suatu perusahaan atau pabrik-pabrik untuk memakai bersama sumberdaya (resouce, misalnya printer) dan saling bertukar informasi.

(2) Metropolitan Area Network (MAN)

Pada dasarnya merupakan versi LAN yang berukuran lebih besar dan biasanya menggunakan teknologi yang sama dengan LAN. MAN dapat mencakup kantor-kantor perusahaan yang letaknya berdekatan atau juga sebuah kota 
dan dapat dimanfaatkan untuk keperluan pribadi (swasta) atau umum. MAN mampu menunjang data dan suara, bahkan dapat berhubungan dengan jaringan televisi kabel.

(3) Wide Area Network (WAN)

Jangkauannya mencakup daerah geografis yang luas, seringkali mencakup sebuah negara bahkan benua. WAN terdiri dari kumpulan mesin - mesin yang bertujuan untuk menjalankan program-program (aplikasi) pemakai.

(4) Internet

Sebenarnya terdapat banyak jaringan didunia ini, seringkali menggunakan perangkat keras dan perangkat lunak yang berbeda-beda . Orang yang terhubung ke jaringan sering berharap untuk bisa berkomunikasi dengan orang lain yang terhubung ke jaringan lainnya. Keinginan seperti ini memerlukan hubungan antar jaringan yang seringkali tidak kampatibel dan berbeda. Biasanya untuk melakukan hal ini diperlukan sebuah mesin yang disebut gateway guna melakukan hubungan dan melaksanakan terjemahan yang diperlukan, baik perangkat keras maupun perangkat lunaknya. Kumpulan jaringan yang terinterkoneksi inilah yang disebut dengan internet.

(5) Jaringan Tanpa Kabel

Merupakan suatu solusi terhadap komukasi yang tidak bisa dilakukan dengan jaringan yang menggunakan kabel. Misalnya orang yang ingin mendapat informasi atau melakukan komunikasi walaupun sedang berada diatas.

\subsection{Analisa Sistem}

Dalam perancangan sistem informasi pembayaran Uang Komite berbasis jaringan pada SMU Negeri 2, dapat digambarkan dengan FOD, DFD dan HIPO.

\section{METODE PENELITIAN}

\subsection{Pengumpulan Data}

Pengumpulan data dilakukan secara langsung ke SMU Negeri 2 dengan mengadakan observasi dan wawancara, dimana observasi malakukan pengamatan langsung ke bagianbagian yang ada hubungannya dengan sistem pelayanan kesehatan, dimana observasi ditujukan agar data yang diperoleh dapat lebih lengkap, Wawancara dilakukan dengan mengajukan pertanyaan lisan dalam usaha untuk melengkapi data yang dibutuhkan dalam merancang sistem.

\subsection{Studi Literatur}

Dalam metode ini dilakukan dengan mencari berbagai buku serta referensi lain yang peneliti butuhkan, tentunya yang berhubungan dengan pelayanan kesehatan, baik dari buku, jurnal maupun dari internet.

\subsection{Teknik Pengembangan}

Teknik pengembangan dilandasi metodologi Object Oriented Analysis and Design $(O O A D)$ dimulai dengan proses menggambarkan kebutuhan sistem, menganalisa sistes, desain sistem, dilanjutkan dengan proses pengimplemantasian sistem ${ }^{[4]}$.

\section{HASIL DAN PEMBAHASAN \\ 4.1. Flow Of Document ( FOD )}

FOD yang diusulkan dimulai pada bagian Siswa yang pada bagian ini memberikan data siswa kepada bagian Bendahara sebanyak 2 (Dua) rangkap, rangkap 2 diarsipkan pada bagian bendahara dan rangkap 1 diproses secara komputerisasi untuk dibuatkan kartu biaya spp yang kemudian di serahkan kepada bagian Siswa. Pada bagian Siswa kartu biaya komite tersebut kemudian dibawa lagi ke bagian Bendahara untuk melakukan pembayaran lalu terbitlah dokumen bukti pembayaran iuran sebanyak 2 (dua) rangkap yang kemudian diproses secara komputerisasi untuk dibuat dokumen kartu biaya komite yang sudah ditandatangani sebanyak 2 (dua) rangkap. Rangkap 1 diserahkan kepada bagian Siswa sedangkan rangkap 2 di proses untuk dibuatkan laporan sebanyak 4 (empat) rangkap. Yaitu laporan daftar siswa, laporan daftar pembayaran biaya komite Laporan siswa yang sudah bayar, dan laporan siswa yang belum bayar kemudian diserahkan pada bagian Kepala TU. Proses selesai pada bagian Kepala TU.

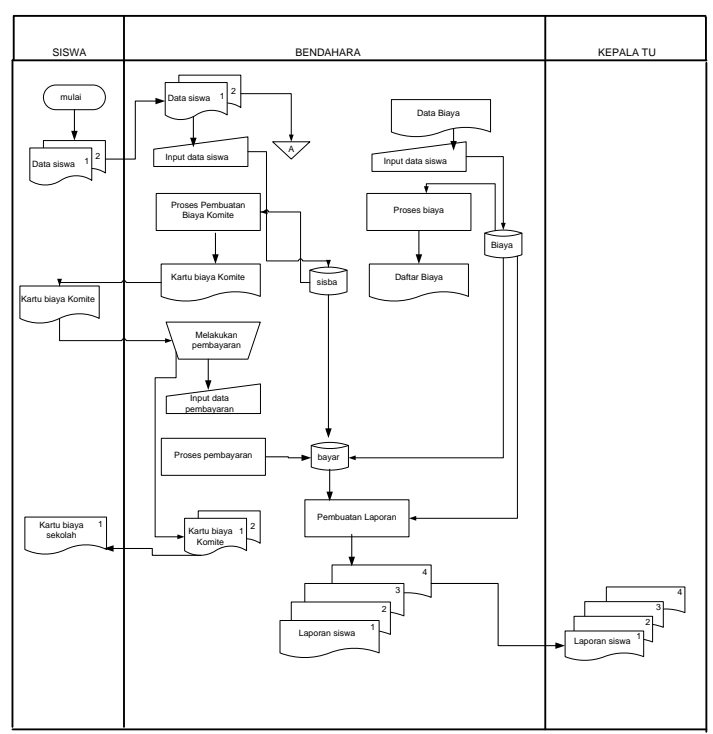

Gambar 1. Data of Documen (FOD)Usulan 


\subsection{HIPO (Hirarchy Plus Input-Proses- output)}

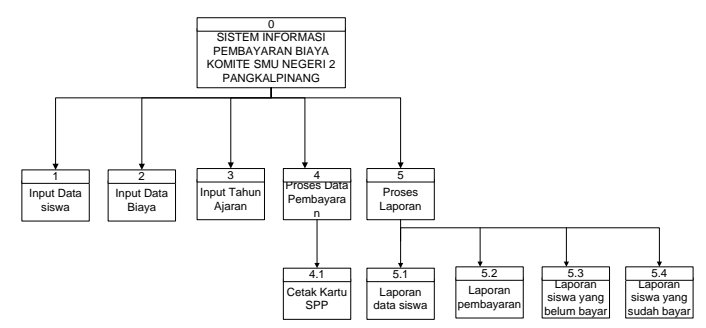

Gambar 2. HIPO (Hirarchy Plus Input-Proses-output)

\subsection{Desain Topologi Jaringan Yang} Digunakan.

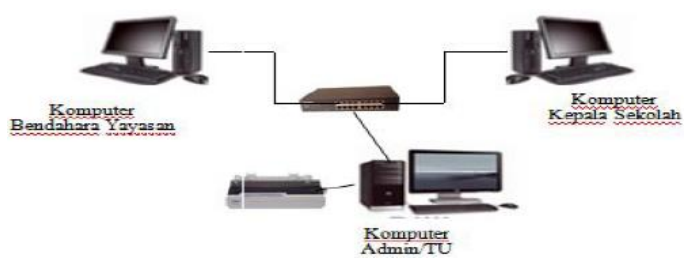

Gambar 3. Desain Topologi Jaringan

Komputer Admin/TU merupakan komputer tempat data base dari sistem pembayaran Biaya komite berada. HUB digunakan sebagai penghubung dua komputer lainnya yakni komputer bendahara yayasan yang diberi hak akses sama seperti Komputer admin/TU, sedangkan computer kepala sekolah hanya diberi hak akses laporan saja. Masing-masing user menggunakan password yang berbeda sebagai keamanan dan identitas pengguna yang telah diberikan hak akses untuk menggunakan sistem ini.

\subsection{Use Case Diagram Pembayaran Biaya Komite}

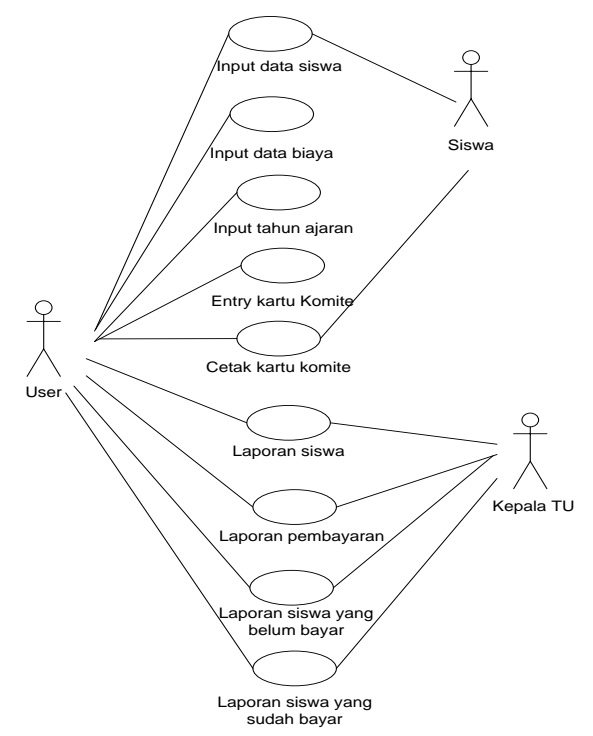

Gambar 4. Use case diagram pembayaran biaya komite

\subsection{Implementasi}

4.5.1. Tampilan Login User

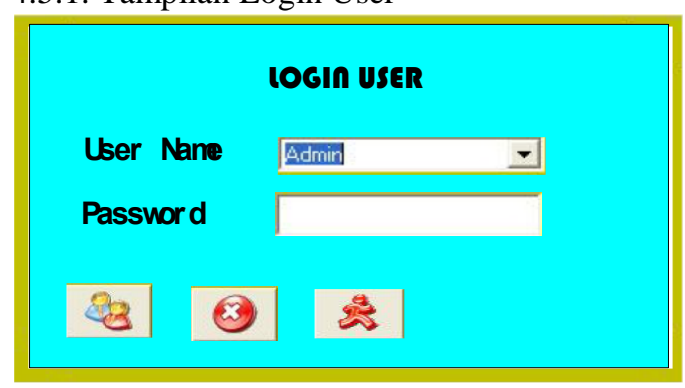

Gambar 5. Login User

Pada gambar 5 merupakan tampilan login user dari sistem sebelum masuk kemenu utama terlebih dahulu mengisikan user name dan password yang benar lalu klik tombol ok, maka akan masuk kemenu utama.

\subsubsection{Tampilan Menu Utama}

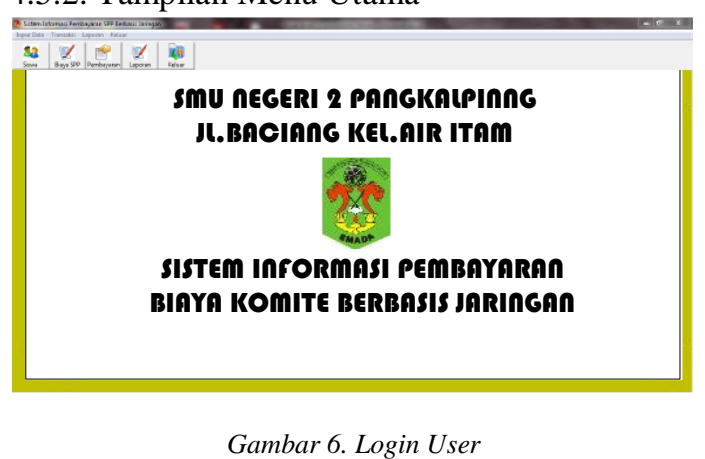

Pada gambar 6 merupakan tampilan menu utama Sistem Informasi Pembayaran biaya Komite. Pada form tersebut terdapat 4 (empat) macam pilihan sistem yaitu :

1. Master Tabel, merupakan menu untuk menginput data siswa dan data biaya komite.

2. Transaksi, merupakan menu untuk menginputkan transaksi pembayaran biaya komite.

3. Laporan, merupakan menu untuk mencetak pembayaran biaya komite berdasarkan perbulan, pembayaran biaya komite per kelas, laporan siswa yang sudah bayar dan laporan siswa yang belum bayar.

4. Keluar, merupakan menu untuk keluar dari program.

\subsubsection{Tampilan Input Siswa}

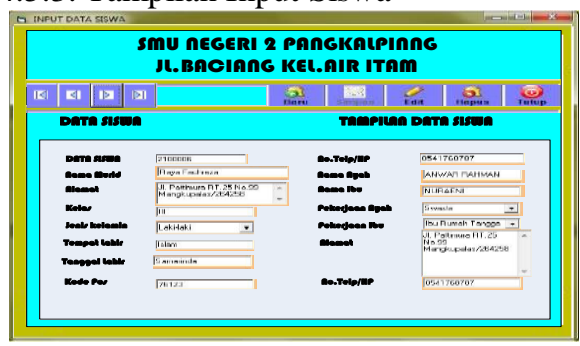

Gambar 7. Input Siswa 
Pada gambar 7 merupakan form untuk menginputkan data siswa. Data yang akan diinput berisikan nis, nama murid, alamat, kelas, jenis kelamin, agama, tempat lahir, tanggal lahir, kode pos, no.telp/hp, nama ayah, nama ibu, pekerjaan ayah.

\subsubsection{Laporan Pembayaran Biaya Komite} Perbulan

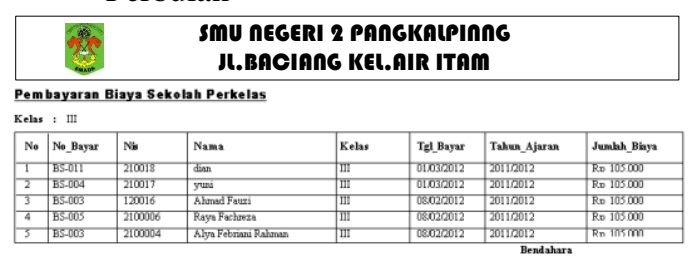

Gambar 8.Laporan Biaya Komite Perbulan

4.5.5. Laporan Pembayaran Biaya Komite Berdasarkan Kelas

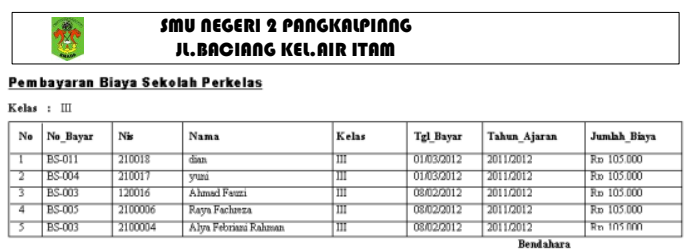

Gambar 9. Laporan Biaya Komite Perkelas

\subsubsection{Kartu Biaya Komite}

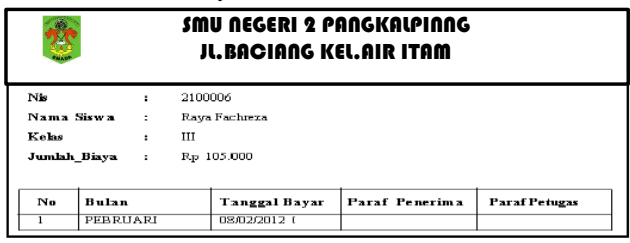

Gambar 10. Kartu Iuran Komite

\section{KESIMPULAN}

\subsection{Kesimpulan}

Setelah penulis mengadakan Penelitian Pada SMU Negeri 2, maka penulis dapat menyimpulkan sebagai berikut:

1. Dengan adanya Sistem Informasi

Pembayaran biaya Komite Berbasis Jaringan pada SMU negeri 2 pangkalpinang dapat melakukan pencetakan kartu biaya Komite serta pelaporannya.

2. Sistem Informasi Pembayaran Biaya Komite Berbasis Jaringan Pada SMU Negeri 2 Pangkalpinang yang telah dibangun dapat melakukan Input Data Siswa,Input Data Biaya komite, Pembayaran Biaya Komite beserta Laporan-Laporan.

3. Sistem Informasi Pembayaran Biaya Komite Berbasis Jaringan Pada SMU Negeri 2 pangkalpinang dapat menghasilkan laporan siswa yang sudah bayar dan dapat menghasilkan laporan siswa yang belum bayar serta dapat juga menghasilkan kartu bayar Komite sekolah.

\subsection{Saran}

Adapun saran yang penulis berikan kepada Sistem Informasi Pembayaran Komite SMU Negeri 2 Pangkalpinang adalah:

1. Agar sistem ini kedepan dapat menampilkan data transaksi yang terjadi baik itu harian, mingguan, bulanan hingga persemester dan satu tahun ajaran.

2. Agar sistem ini dapat menampilkan informasi tentang pembayaran selain dilingkungan internal sekolah juga informasinya dapat digunakan dilingkungan eksternal yaitu para wali murid untuk mengetahui informasi pembayaran Biaya Komite siswa yang bersangkutan.

3. Agar sistem ini kedepannya dapat dikembangkan dengan menggunakan database Mysql agar keamanan datanya lebih terjamin.

4. Agar sistem ini dikembangkan sehingga laporan yang ditampilkan bisa dalam bentuk grafik.

\section{DAFTAR PUSTAKA}

[1] Agus, 2003, Sistem Informasi Manajemen terjemahan Hendra Teguh Edisi ketujuh, Jakarta : Buana Ilmu Komputer,.

[2] Gordon B. Davis, 2001, Pengantar Sistem Informasi Manajemen, Yogyakarta. : Andi Offset.

[3] HM, Jogiyanto, 2003, Analisis dan Desain Sistem Informasi, Yogyakarta : Andi Offset.

[4] Dennis,Alan., et al. "System Analysis And Design with UML Version 2.0". Edisi 2. USA : Indiana University.2005

[5] Kadir Abdul, 2001, Konsep dan Tuntunan Praktis Basis Data, Yogyakarta : Andi Offsest

[6] Kristanto, 2003, Pengantar Sistem Informasi Manajemen, Yogyakarta : Andi Offset.

[7] LPKBM Madcoms Madiun, 2001, Seri Panduan Pemrograman Microsoft Visual Basic 6.0, Yogyakarta : Andi Offset.

[8] Margono, 2002, Sistem Informasi Manajemen terjemahan Hendra Teguh Edisi ketujuh, Jakarta : Buana Ilmu Komputer,.

[9] Mcleod Raymon, 2001, Sistem Informasi Manajemen terjemahan Hendra Teguh Edisi ketujuh, Jakarta : Buana Ilmu Komputer, 
[10] Teguh, 2001, Sistem Informasi Manajemen terjemahan Hendra Teguh Edisi ketujuh, Jakarta : Buana Ilmu Komputer,

[11] Yuhefizar, 2003, Tutorial Komputer ,ilmu Komputer.com di akses 28 Desember 2011. 